\title{
PENGARUH PENGETAHUAN TERHADAP IMPLEMENTASI SASARAN KESELAMATAN PASIEN
}

\author{
MEGA CERIA PURNAMA ZEBUA
}

\section{$\underline{\text { Megaceria25@gmail.com }}$}

\begin{abstract}
ABSTRAK
Latar Belakang: WHO menyatakan keselamatan pasien merupakan masalah kesehatan masyarakat yang serius. Kesalahan medis dapat disebabkan oleh faktor sistem dan faktor manusia. Keselamatan pasien sudah menjadi isu yang sangat berpengaruh terhadap pandangan khalayak umum pada sebuah Rumah Sakit. Sehingga keselamatan pasien menjadi alat untuk mengukur dan mengevaluasi kualitas pelayanan Rumah sakit. Kepercayaan masyarakat terhadap mutu pelayanan kesehatan dapat ditingkatkan dengan adanya status terakreditasi karena standar-standar yang ditetapkan dalam akreditasi dibuat untuk memenuhi hak-hak pasien. Tujuan:.Untuk mengetahui apakah pengetahuan berpengaruh dalam implementasi sasaran keselamatan pasien Metode: Penelitian explanatory research Kesimpulan: Kualitas rumah sakit tidak hanya terlihat dari bangunan megah, dokter-dokter berpengalaman, obatobatan yang lengkap, dan peralatan medis yang serba canggih. Rumah sakit dituntut untuk memberikan pelayanan kesehatan terbaik dan lebih terbuka pada masyarakat.
\end{abstract}

Kata Kunci: Keselamatan Pasien, 6 SKP, K3RS 


\section{LATAR BELAKANG}

Keselamatan pasien sudah menjadi isu yang sangat berpengaruh terhadap pandangan khalayak umum pada sebuah Rumah Sakit. Sehingga keselamatan pasien menjadi alat untuk mengukur dan mengevaluasi kualitas pelayanan Rumah sakit. (Setiyani, Zuhrotunida, \& Syahridal, 2016)

Menurut Permenkes Nomor 1691 Ada enam sasaran keselamatan pasien yaitu Ketepatan identifikasi pasien; Peningkatan komunikasi yang efektif; Peningkatan keamanan obat yang perlu diwaspadai; Kepastian tepat- lokasi, tepat-prosedur, tepat-pasien operasi; Pengurangan risiko infeksi terkait pelayanan kesehatan; dan Pengurangan risiko pasien jatuh.

WHO menyatakan keselamatan pasien merupakan masalah kesehatan masyarakat yang serius. Kesalahan medis dapat disebabkan oleh faktor sistem dan faktor manusia. Insiden keselamatan pasien yang merugikan adalah terkait dengan prosedur bedah (27\%), kesalahan pengobatan $(18,3 \%)$ dan kesehatan infeksi terkait perawatan $(12,2 \%)$ (WHO, 2017). Sedangkan di Eropa, kejadian pasien dengan risiko infeksi sebanyak $83,5 \%$ dan bukti kesalahan medis menunjukkan 5072,3\%. (Neri, Lestari, \& Yetti, 2018)
Kualitas rumah sakit tidak hanya terlihat dari bangunan megah, dokterdokter berpengalaman, obat-obatan yang lengkap, dan peralatan medis yang serba canggih. Rumah sakit dituntut untuk memberikan pelayanan kesehatan terbaik dan lebih terbuka pada masyarakat. Kepercayaan masyarakat terhadap mutu pelayanan kesehatan dapat ditingkatkan dengan adanya status terakreditasi karena standar-standar yang ditetapkan dalam akreditasi dibuat untuk memenuhi hak-hak pasien. (Pambudi, Sutriningsih, \& Yasin, 2018)

Maksud dari Sasaran Keselamatan Pasien adalah mendorong peningkatan spesifik dalam keselamatan pasien. Sasaran ini menyoroti area yang bermasalah dalam pelayanan kesehatan dan menguraikan tentang solusi atas konsensus berbasis bukti dan keahlian terhadap permasalahan ini. Patient Safety adalah suatu sistem yang mencegah terjadinya Kejadian Tidak Diharapkan (KTD) akibat tindakan yang dilakukan atau bahkan tidak dilakukan oleh tenaga medis maupun non medis. Sistem tersebut meliputi: assessmen resiko, identifikasi dan pengelolaan hal yang berhubungan dengan risiko pasien, pelaporan dan analisis insiden, kemampuan belajar dari insiden dan tindak lanjutnya serta implementasi solusi untuk meminimalkan timbulnya resiko. 


\section{METODE}

Rancangan penugasaan kajian ini menggunakan buku teks, buku referensi, ebook, jurnal dengan menganalisa dan kajian bebas. Penelitian ini menggunakan jenis penelitian explanatory research. Penelitian eksplanatori ( explanatory research ) bersifat penjelasan dan bertujuan untuk menguji suatu teori atau hipotesis guna memperkuat atau bahkan menolak teori atau hipotesis hasil penelitian yang sudah ada.

\section{HASIL DAN PEMBAHASAN}

Pengetahuan adalah hasil ketika seseorang mencari tau sesuatu melalui alat indera yang dia miliki, sehingga dengan pengetahuan tersebut seseorang dapat melakukan sesuatu sesuai dengan yang dia ketahui.

Ketika seorang perawat mengetahui apa saja aspek sasaran keselamatan pasien maka perawat melakukan pelayanan sesuai dengan apa yang dia ketahui dan pelajari. Jika sudah sesuai maka tidak akan terjadi masalah. Namun banyak perawat yang mengabaikan aspek aspek tersebut sehingga kualitas pelayanan menurun.

Pendidikan seorang perawat yang bekerja dapat mempengaruhi pengimplementasian sasaran keselamatan pasien. (Surahmat, Neherta, \& Nurariati, 2018).

Pengimplementasian

Sasaran

Keselamatan Pasien sangat berpengaruh terhadap kualitas pelayanan Rumah sakit. Menurut Kotler dan Keller tahun 2007 menyatakan bahwa "kualitas pelayanan harus dimulai dari kebutuhan pelanggan dan berakhir pada persepsi pelanggan, dimana persepsi pelanggan terhadap kualitas pelayanan merupakan penilaian menyeluruh atas keunggulan suatu pelayanan". Hal ini berarti bahwa citra kualitas yang baik bukan berdasarkan sudut pandang atau persepsi pihak penyedia jasa, yaitu perusahaan akan tetapisudut pandang penilaian persepsi pelanggan. Dalam hal ini, konsumen adalah pihak yang mengkonsumsi dan menikmati jasa perusahaan, sehingga merekalah yang seharusnya menentukan kualitas jasa. (Suarjana, 2015)

Ada 6 Sasaran Keselamatan Pasien

1. Mengidentifikasi pasien dengan benar.

2. Meningkatkan komunikasi yang efektif.

3. Meningkatkan keamanan obatobatan yang harus diwaspadai.

4. Memastikan lokasi pembedahan yang benar, prosedur yang benar, 
pembedahan pada pasien yang benar.

5. Mengurangi risiko infeksi akibat perawatan kesehatan.

6. Mengurangi risiko cedera pasien akibat terjatuh.

Hal hal dasar yang dapat dilakukan untuk meningkatkan sasaran keselamatan kerja ialah: memberikan gelang identitas, memberikan tanda pada pasien jika pasien khusus seperti (alergi), resiko jatuh dari tempat tidur, penggunaan APD, mencuci tangan, pencegahan infeksi nosokomial. (Nuryati, 2019)

Hal hal yang dapat menyebabkan kecelakaan pasien adalah Kesalahan dalam mengidentifikasi pasien, Komunikasi tidak efektif, penggunaan obat high alert yang tidak aman, tidak tepat lokasi, pencegahan pasien jatuh yang buruk.

Dalam kode etik keperawatan disebutkan bahwa perawat memiliki tanggung jawab agar senantiasa memelihara mutu pelayanan keperawatan yang tinggidisertai kejujuran profesional yang menerapkan pengetahuan serta ketrampilan keperawatan sesuai dengan kebutuhan klien. Dalam hubungannya, perawat berkewajiban melindungi klien dari tenaga kesehatan yang memberikan pelayanan kesehatan secara tidak kompeten, tidak etis dan ilegal. (Cahyono, 2015)
Dari beberapa jurnal menagatakan bahwa mencuci tangan ada 5 waktu yaitu sebelum ke pasien, setelah dari pasien, setelah melakukan tindakan aseptic, setelah terkena cairan pasien, dan setelah dari lingkungan pasien. Selain itu,hambatan untuk cuci tangan adalah lupa.

Solusi yang dilakukan partisipan untuk meningkatkan kepatuhan dalam cuci tangan adalah dengan berusaha membiasakan dan merubah mindset bahwa cuci tangan bukan semata - mata untuk mesukseskan program rumah sakit, tapi juga untuk kebaikan diri sendiri agar tidak tertular penyakit dari rumah sakit. Solusi tersebut sesuai dengan penelitian oleh Janet E Clark (2013) bahwa cara untuk meningkatkan kepatuhan dalam cuci tangan adalah melalui behavior therapy atau terapi untuk membentuk kebiasaan yang merupakan sebuah proses berkesinambungan. (Isnaini, 2014).

$$
\text { Dalam memimplementasikan }
$$
semua sasaran keselamatan kerja di butuhkan kesadaran diri setiap individu yang ada dalam cakupan sistem rumah sakit. Kualitas memiliki hubungan yang erat dengan kepuasan pasien. (Manik, 2019) 


\section{KESIMPULAN}

6 Sasaran Keselamatan Pasien

1. Mengidentifikasi pasien dengan benar.

2. Meningkatkan komunikasi yang efektif.

3. Meningkatkan keamanan obatobatan yang harus diwaspadai.

4. Memastikan lokasi pembedahan yang benar, prosedur yang benar, pembedahan pada pasien yang benar.

5. Mengurangi risiko infeksi akibat perawatan kesehatan.

6. Mengurangi risiko cedera pasien akibat terjatuh.

Pengetahuan yang banyak akan 6 Sasaran Keselematan Pasien dapat membuat pengimplemntasian lebih nyata terjadi, dan dengan adanya kesadaran diri akan pentingnya 6 sasaran tersebut maka pelayanan rumah sakit akan semakin baik. 6 sasaran keselamatan pasien menjadi alat untuk mengukur kualitas suatu rumah sakit. Kualitas rumah sakit tidak hanya terlihat dari bangunan megah, dokter-dokter berpengalaman, obat-obatan yang lengkap, dan peralatan medis yang serba canggih. Rumah sakit dituntut untuk memberikan pelayanan kesehatan terbaik dan lebih terbuka pada masyarakat.

\section{DAFTAR PUSTAKA}

Cahyono, A. (2015). hubungan karakteristik dan tingkat pengetahuan perawat terhadap pengelolaan keselamatan pasien di rumah sakit.

Fadriyanti, Y., \& Suryarinilsih, Y. (2018). HUBUNGAN JAM KERJA DAN KARAKTERISTIK PERAWAT PELAKSANA DENGAN.

Isnaini, N. (2014). Pengalaman perawat pelaksana dalam menerapkan keselamatan pasien. Jurnal Manajemen Keperawatan.

Manik, S. (2019). Pengaruh Kualitas pelayanan terhadap kepuasan pasien pada Rumah Sakit Thursina di DURI.

Neri, R. A., Lestari, Y., \& Yetti, H. (2018). Analisis Pelaksanaan Sasaran Keselamatan Pasien diRawat Inap RSU Daerah Padang Pariaman. Jurnal kesehatan Andalas, 49.

Nuryati, A. (2019). Pengetahuan Mahasiswa keperawatan tentang sasaran keselamatan pasien.

Pambudi, Y. D., Sutriningsih, A., \& Yasin, D. D. (2018). Faktor yang mempengaruhi perawat dalam penerapan 6 SKP pada Akreditasi 
JCI di ruang rawat inap . Nursing News, 731.

Setiyani, M. D., Zuhrotunida, \& Syahridal. (2016). Implementasi Sasaran Keselamatan Pasien Di Ruang Rawat Inap Rsu Kabupaten Tangerang. JKTF, 60.

Suarjana, A. G. (2015). PENGARUH KUALITAS PELAYANAN TERHADAP KEPUASANDALAM RANGKA MENCIPTAKAN LOYALITAS PASIENPADA RUMAH SAKIT UMUM DAERAH SANJIWANIKABUPATEN GIANYAR.

Surahmat, R., Neherta, M., \& Nurariati. (2018). Hubungan Karakteristik Perawat Terhadap Pelaksanaan sasaran Keselamatan Pasien pasca Akreditasi. JIUBJ, 07. 